Food Engineering

Elsevier Editorial System(tm) for Journal of

Manuscript Draft

Manuscript Number: JFOODENG-D-12-01683R1

Title: Quality and safety driven optimal operation of deep-fat frying of potato chips.

Article Type: Research Article

Keywords: deep-fat frying; acrylamide; model identification; dynamic optimization.

Corresponding Author: Dr Eva Balsa-Canto, PhD

Corresponding Author's Institution: Spanish Council for Scientific Research, CSIC

First Author: Ana Arias-Mendez, MSc

Order of Authors: Ana Arias-Mendez, MSc; Alexander Warning, MSc; Ashim K Datta, Professor; Eva Balsa-Canto, PhD

Abstract: Increasing oil temperature and heating duration in deep-fat frying of potato chips can improve textural quality but worsen the chemical safety of acrylamide formation. Optimal design of this complex process is formulated as a non-linear constrained optimization problem where the objective is to compute the oil temperature profile that guarantees the desired final moisture content while minimizing final acrylamide content subject to operating constraints and the process dynamics. The process dynamics uses a multicomponent and multiphase transport model in the potato as a porous medium taken from literature. Results show that five different heating zones offer a good compromise between process duration (shorter the better) and safety in terms of lower acrylamide formation. A short, high temperature zone at the beginning with a progressive decrease in zone temperatures was found to be the optimal design. The multi-zone optimal operating conditions show significant advantages over nominal constant temperature processes, opening new avenues for optimization. 
1 Quality and safety driven optimal operation of deep-fat

2

3

4

5

6

7 frying of potato chips.

\author{
A. Arias-Mendez ${ }^{\mathrm{a}}$, A. Warning ${ }^{1}$, A. K. Datta ${ }^{1}$, E. Balsa-Canto ${ }^{\mathrm{a}, *}$ \\ anaarias@iim.csic.es,adw88@cornell.edu,akd1@cornell.edu, ebalsa@iim.csic.es \\ ${ }^{a}$ Bioprocess Engineering Group, IIM-CSIC, C/Eduardo Cabello 6, 36208, Vigo-Spain \\ ${ }^{b}$ Department of Biological and Environmental Engineering, Cornell University, 208 \\ Riley-Robb, Ithaca, NY 14853-5701, United States
}

\title{
8 Abstract
}

Increasing oil temperature and heating duration in deep-fat frying of potato chips can improve textural quality but worsen the chemical safety of acrylamide formation. Optimal design of this complex process is formulated as a non-linear constrained optimization problem where the objective is to compute the oil temperature profile that guarantees the desired final moisture content while minimizing final acrylamide content subject to operating constraints and the process dynamics. The process dynamics uses a multicomponent and multiphase transport model in the potato as a porous medium taken from literature. Results show that five different heating zones offer a good compromise between process duration (shorter the better) and safety in terms of lower acrylamide formation. A short, high temperature zone at the beginning with a progressive decrease in zone temperatures was found to be the optimal design. The multi-zone optimal operating conditions show significant advantages over nominal constant temperature processes, opening new avenues for optimization.

9 Keywords: deep-fat frying, acrylamide, model identification, dynamic

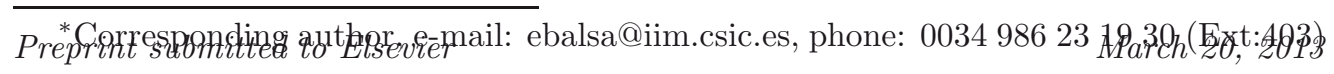


optimization

\section{Introduction}

Frying generates tasty products that have crispy crusts, tempting aromas and visual appeal. These unique properties make fried foods a major part of the prepared foods market and therefore deep-fat frying is still one of the most important unit operations in the food processing industry.

Type of oil, oil temperature, and duration of cooking greatly affect the final quality attributes of fried foods. Often in literature, the quality is related to the oil uptake and oil deterioration. Oil uptake occurs during frying due to replacement evaporated water by oil and during post frying when it is absorbed due to the vacuum from cooling. Hydrolysis and oxidation contribute to the development of rancid flavors deteriorating oil quality (Saguy and Dana, 2003).

Recent works showed that fried foods are a significant source of dietary acrylamide (Tareke et al., 2002; Zhang et al., 2005), an emerging factor that has been associated with cancer risk and neurotoxic effects. Although the details of acrylamide synthesis are not fully understood, the Maillard-driven generation of flavor and color in the frying process can be linked to the formation of acrylamide (Medeiros-Vinci et al., 2011).

The increased awareness of the consumers to the relationship between food, nutrition and health has emphasized the need to design (pre-)process conditions, product specifications and type of oil so as to improve product quality and to minimize oil uptake and acrylamide formation. In this regard some recommendations may be found in, for example, Alvarez et al. (2000); 
Mestdagh et al. (2008); Brigatto-Fontes et al. (2011).

However, these recommendations are often obtained by means of response surface models thus having a number of important drawbacks due to the empirical, local and stationary nature of the simple algebraic models used.

A fundamental understanding of the deep-fat frying process and the application of adequate optimization techniques could lead to new equipment and operation designs that may improve safety and quality of the final product.

To understand the mechanisms involved in the process, mathematical models were developed, from the first attempts that included heat, moisture and fat transfer in the frying of foods (Ateba and Mittal, 1994; Moreira et al., 1995; Farkas et al., 1996) to the most recent porous media based models which also account for texture and acrylamide evolution (Halder et al., 2007; Thussu and Datta, 2012; Warning et al., 2012).

Bassama et al. (2012) considered, via simulation, two types of transient oil temperature profiles in order to asses the impact on the final acrylamide content. The first oil temperature profile started at a high temperature, followed by a lower one and the second frying oil temperature profile was vice-versa. Their work concludes that the first type of profile results in significant reductions on the final acrylamide content.

However at the time of designing processing profiles, not only should have acrylamide content been taken into account, but quality attributes and processing time. Of course solving such a problem via simulation is rather complicated, if not impossible, due to the numerous degrees of freedom and constraints. This work proposes the use of advanced model based optimization techniques (Banga et al., 2003, 2008) to design optimized frying processes 
to ensure appropriate safety through minimized final acrylamide content and quality by guaranteeing the desired specifications in terms of color and texture.

\section{Theory}

\subsection{Formulation of the optimization problem}

In industry, the traditional operation conditions for frying potato chips consist of immersing the chips in continuous fryers where the frying oil is held at high temperatures. The process duration is long enough (typically between 1-3 minutes) to guarantee a desired final color, texture, and a final moisture level less than $2 \%$ of the initial moisture content (Brennan, 2006).

The objective of the present work is to formulate and solve a general dynamic optimization problem to find the operating conditions (oil temperature and process duration) that produces the desired quality attributes while minimizing the final acrylamide content. Mathematically stated as:

Find $T_{\text {oil }}(t)$ and $t_{f}$ to minimize $c_{A A}\left(t_{f}\right)$ such that:

$$
\begin{aligned}
& T_{\text {oil }_{\min }} \leq T_{\text {oil }} \leq T_{\text {oilmax }} \\
& t_{f} \leq t_{f, \max } \\
& Q C\left(t_{f}\right)<=0 \\
& \Phi\left(S_{w}, S_{o}, S_{g}, T, M, P, w, c_{A A}, T_{o i l}, \boldsymbol{\kappa}, \boldsymbol{\xi}, t\right)=0
\end{aligned}
$$

where $T_{o i l}, t_{f}$, and $c_{A A}$ are the oil temperature, process duration, and acrylamide content respectively. QC stands for the quality constraint defined in equation 5. 
Equation 3 defines the constraints for quality as defined by color, texture, and moisture content. Pedreschi et al. $(2005,2006)$ showed that the color in the product during the frying process follows a first order kinetics. The higher the red component of the color, the darker the potato and the worse the commercial acceptance of the final product. In addition, these authors show how acrylamide content is linearly correlated with the color at $1.8 \%$ of the initial moisture content whereas Pedreschi et al. (2005) show a clear correlation between the increase of acrylamide content and the increase of redness. In this optimization work, it is assumed that the minimization of acrylamide content also minimizes redness of the product. Regarding texture, Thussu and Datta (2012) presented a mechanistic model to predict Young's module development during frying. Their results suggest that there is not critical difference in considering the texture or the moisture content to control the process duration. Therefore, the constraint imposed in the optimization will be related to the moisture content at the end of the process. In this way, the solution of the equations to predict texture evolution is not really necessary. The quality related inequality constraint now becomes:

$$
M\left(t_{f}\right)-2 \leq 0
$$

where $M$ is the percentage of the final moisture content, which is intended to be $2 \%$ or lower at the end of the process.

There is an additional set of constraints (Equations 4) which corresponds to the system dynamics from the mathematical model of the process which describes the evolution of the saturation of water, oil and vapor $\left(S_{w}, S_{o}, S_{g}\right)$, product temperature $(T)$, moisture content $(M)$, pressure $(P)$, water vapor 
mass fraction $\left(\omega_{v}\right)$ and acrylamide content $c_{A A}$; the corresponding spatial and temporal derivatives, as functions of the spatial coordinates $(\boldsymbol{\xi})$; time $(t)$ and oil temperature $\left(T_{\text {oil }}\right)$. The vector $\boldsymbol{\kappa}$ keeps all model thermo-physical and kinetic parameters.

\subsection{Mathematical model of the process}

In the deep-fat frying process, water containing foodstuff is immersed into oil or fat at high temperatures (typically between 160 and $180^{\circ} \mathrm{C}$, Pedreschi et al. (2005)). The high temperature induces water evaporation and the formation of a thin crust. Due to the evaporation, the water is gradually transported to the boundary layer whereas the oil is absorbed by the food replacing some of the lost water. As soon as the transfer of water ends, the temperature inside the food starts to rise and the typical deep-frying sensory characteristics begin to develop.

A multiphase porous media based model describing heat, mass and momentum transfer and acrylamide kinetics within a potato chip will be used. The potato chip is assumed to be a porous media where the pores are filled with three transportable phases: liquid water, oil, or gas (mixture of water vapor and air). The model considers a 2D geometry as illustrated in Figure 1, the potato chip is assumed to be cylindrical and heated from outside therefore axi-symmetry can be assumed. The physical mechanisms and corresponding equations derivation are described in detail in Warning et al. (2012) and Halder et al. (2007). The final system of equations is presented in Appendix A.

It should be noted that most of the thermo-physical and kinetic parameters present in the model may be found in the literature (see Table A.1 
in the Appendix) but the heat transfer $(h)$ and the surface oil saturation $S_{o, s u r f}$. Previous works provided different parameter values for different oil temperature values. However for the purpose of dynamic optimization either a unique value for the parameters or a functional dependency with the oil temperature is required. In either case, unknown model parameters have to be identified from experimental data.

\subsubsection{Model parametric identification}

The objective of parametric identification (model calibration or parameter estimation) is to compute a unique value for the vector of unknown parameters $(\boldsymbol{\theta})$, which either coincides or is included in the vector $\boldsymbol{\kappa}$, so as to minimize the distance among experimental data and model predictions. In this work, this distance is quantified by the sum of the weighted squared differences among experimental and simulated data (weighted least squares).

The problem is thus formulated as a non-linear constrained optimization problem, as follows:

Find $\boldsymbol{\theta} \in R^{n_{\theta}}$ so as to minimize:

$$
J_{w l s q}(\boldsymbol{\theta})=\sum_{i=1}^{n_{e}} \sum_{j=1}^{n_{o}^{e}} \sum_{k=1}^{n_{s, o}^{e}} q_{i, j, k}\left(\tilde{y}_{i, j, k}-y_{i, j, k}(\boldsymbol{\theta})\right)^{2},
$$

142 subject to the system dynamics plus bounds on the parameters:

$$
\begin{aligned}
& \Phi\left(S_{w}, S_{o}, S_{g}, T, M, P, w, c_{A A}, T_{o i l}, \boldsymbol{\theta}, \boldsymbol{\xi}, t\right)=0 \\
& \boldsymbol{\theta}_{\text {min }} \leq \boldsymbol{\theta} \leq \boldsymbol{\theta}_{\text {max }}
\end{aligned}
$$


where $n_{e}, n_{o}^{e}$ and $n_{s, o}^{e}$ correspond to the number of experiments, the number of observed quantities per experiment and the number of samples (in time and space) per observed quantity and experiment, respectively. The weight values $q_{i, j, k}$ quantify the relative importance that is assigned to a given experimental data. $\boldsymbol{\theta}_{\min }$ and $\boldsymbol{\theta}_{\max }$ correspond to the minimum and maximum acceptable value for the parameters. $\tilde{y}_{i, j, k}$ corresponds to a given experimental data and $y_{i, j, k}$ corresponds to the model prediction. Hence, 6 represents the result of simulating the model and evaluating the measured quantities at sampling time $k$ under the experimental conditions $e$. The observed quantities in this case correspond to the acrylamide, moisture Eq. 9 and oil content Eq. 10:

$$
\begin{aligned}
& M(t)=100 \times \frac{1}{M(0)} \int_{S} \frac{S_{w} \rho_{w} \varphi}{\rho_{s}(1-\varphi)} d S \\
& \operatorname{oil}(t)=\int_{S} \frac{S_{o} \rho_{o} \varphi}{\rho_{s}(1-\varphi)} d S
\end{aligned}
$$

and the parameters to be estimated are the convective heat transfer coefficient $(h)$ and the surface oil saturation $S_{o, \text { surf }}$.

Therefore the parameter estimation problem reads:

Find $h$ and $S_{o, \text { surf }}$ to minimize:

$$
\begin{aligned}
& J_{w l s q}\left(h, S_{o, s u r f}\right)=\sum_{i=1}^{n_{e}} \sum_{k=1}^{n_{s, A A}^{e}}\left(\frac{\tilde{c}_{A A_{i, k}}-c_{A A_{i, k}}}{\max \left(\tilde{c}_{A A_{i}}\right)}\right)^{2}+ \\
& \sum_{i=1}^{n_{e}} \sum_{k=1}^{n_{s, M}^{e}}\left(\frac{\tilde{M}_{i, k}-M_{i, k}}{\max \left(\tilde{M}_{i}\right)}\right)^{2}+\sum_{i=1}^{n_{e}} \sum_{k=1}^{n_{s, o}^{e}}\left(\frac{\tilde{o} l_{i, k}-o i l_{i, k}}{\max \left(\tilde{o} l_{i}\right)}\right)^{2}
\end{aligned}
$$


subject to:

$$
\begin{aligned}
& \Phi\left(S_{w}, S_{o}, S_{g}, T, M, P, w, c_{A A}, T_{o i l}, h, S_{o, s u r f}, \boldsymbol{\xi}, t\right)=0 \\
& 40 \leq h \leq 160\left(W m^{-2} K^{-1}\right) \\
& 0.055 \leq S_{o, \text { surf }} \leq 0.22
\end{aligned}
$$

The weights $q_{i, j, k}$ were selected so as to take into account the different orders of magnitude of the observed quantities. $n_{s, A A}^{e}, n_{s, M}^{e}$ and $n_{s, o}^{e}$ correspond to the number of sampling points for acrylamide, moisture and oil content, respectively, for the experiment $e$. The total amount of experimental data used is represented as $N_{d}$.

In order to asses the quality of the parameter estimates, several possibilities exist (Walter and Pronzato, 1997). Bootstrap or jack-knife approaches allow to compute robust confidence intervals. However, the associated computational cost make it difficult to use these methods for large scale models. Alternatively, confidence intervals may be obtained through the covariance matrix. The confidence interval of a given parameter $\boldsymbol{\theta}_{i}^{*}$ is then given by:

$$
\pm t_{\alpha / 2}^{\gamma} \sqrt{\mathbf{C}_{\mathbf{i i}}}
$$

where $t_{\alpha / 2}^{\gamma}$ is given by Students t-distribution, $\gamma=N_{d}-n_{\theta}$ corresponds to the number of degrees of freedom and $\alpha$ is the (1- $\alpha) 100 \%$ confidence interval selected, typically $95 \%$ is used.

For non-linear models, there is no exact way to obtain C. Therefore the use of first or second order approximations to the function $J_{w l s q}$ in the vicinity of the optimal solution $\boldsymbol{\theta}_{i}^{*}$ has been suggested to compute covariance matrix estimations. The Crammèr-Rao inequality establishes that under 
certain assumptions on the number of data and non-linear characters of the model, the covariance matrix may be approximated by the inverse of the Fisher information matrix. The Fisher information matrix is a first order approximation to the weighted least squares function. However, for highly non-linear models, a first order approximation to the weighted least squares seems inappropriate. Instead, the Hessian of the weighted least squares as evaluated in the optimum $\left(\mathbf{H}\left(\boldsymbol{\theta}^{*}\right)\right)$ can be used to estimate the covariance matrix as follows:

$$
\mathbf{C}\left(\boldsymbol{\theta}^{*}\right)=\frac{2}{\gamma} J_{w l s q}\left(\boldsymbol{\theta}^{*}\right) \mathbf{H}\left(\boldsymbol{\theta}^{*}\right)^{-1}
$$

\section{Materials and methods}

\subsection{Experimental data}

For the purpose of parameter estimation data taken from the works by Garayo and Moreira (2002) and Granda (2005) were used. The data consists on three times series data for acrylamide, moisture and oil content obtained at $n_{e}=3$ different oil temperatures $\left(150,165\right.$ and $\left.180^{\circ} \mathrm{C}\right)$, with $n_{s, A A}^{e}=9$, $n_{s, M}^{e}=7$ and $n_{s, o}^{e}=9$.

\subsection{Numerical methods}

\subsubsection{Simulation}

The equations of the model have been solved in COMSOL Multiphysics 3.5a , a commercial finite element software. The Convection and Diffusion module was used to solve for water, oil, and acrylamide mass conservation while Maxwell-Stefan Diffusion and Convection was used to gas mass fraction 
and Darcy's Law and Convection and Conduction were used to solve for pressure and temperature respectively. Since the solution of the parametric identification and the dynamic optimization problems require the solution of the model hundreds of times, the spatial and temporal mesh were selected so as to offer a good compromise between the quality of the solution as compared to a dense mesh and the computational effort. The selected mesh consists of $20 \times 10$ rectangular elements and the initial time step size is $1 e^{-6} s$ being output time step of $1 \mathrm{~s}$. This translates into a computational cost of approximately $40 \mathrm{~s}$ to simulate $1.5 \mathrm{~min}$ of frying process on a standard PC (4 Cores and 3.25GB RAM, processor speed of $2.83 \mathrm{GHz}$ ).

\subsubsection{Dynamic Optimization}

Both the parametric identification and the process optimization problems presented in Section 2 can be formulated as non-linear programming problems (NLP) with dynamic and algebraic constraints. For the case of process optimization under transient oil temperature profiles, and taking into account the distributed nature of the model at hand, the control vector parameterization (CVP) approach can be used to transform the original problem into a constrained NLP. In this work, a piece-wise constant approximation of the oil temperature profile was considered, which translates, in practice, to the case where the chips are moving through different regions in the fryer that may be set at different temperatures.

To solve the resulting NLP problems, it is important to take into account that non-linear constrained problems may be non-convex, therefore the use of global optimization methods is required (Banga et al., 2003). In this regard, and considering that the computational effort devoted to simulation 
222 is rather significant a hybrid global-local method is suggested to enhance the 223 efficiency of the optimization process. In this work, a scatter search based 224 approach (SSm) presented by Egea et al. (2007) has been selected since it 225 has demonstrated to offer a good compromise efficiency-robustness in the 226 solution of complex optimization and dynamic optimization problems (Egea 227 et al., 2009).

${ }_{228}$ The parametric identification problem was formulated and solved using 229 the recently developed MATLAB toolbox AMIGO (Advanced Model Identification using Global Optimization, Balsa-Canto and Banga (2011)). The control vector parameterization was implemented in MATLAB to solve the process dynamic optimization problem with SSm. In both cases, COMSOL was called from MATLAB to perform the model simulations. Figure 2 presents a schematic representation of the solution approaches for both types of problems. 


\section{Results and discussion}

\subsection{Model parametric identification}

The parametric identification resulted in the following optimal parameter values $h^{*}=83.7 \mathrm{Wm}^{-2} \mathrm{~K}^{-1}$ and $S_{o, \text { surf }}^{*}=0.1377$. The best fit is shown in Figures 3.

It should be noted that despite the fact that the parameters do not depend on the experiment as in previous works, the value of the cost function has improved from $J_{w l s q}=4.4$ to $J_{w l s q}=3.5$. Figures 4 illustrate the differences between previous and current approximations in terms of the mean relative prediction error, revealing that the use of the optimal value for $h$ and $S_{o, \text { surf }}$ results in a considerable improvement in the overall predictive capabilities of the model and enables the possibility of using the model throughout the range of operation conditions with unique values on the parameters. Following the same procedure, a functional dependency of the parameters on the oil temperature could be identified if more data became available.

Confidence intervals for the parameters were calculated through the Hessian of the weighted least squares as evaluated in the optimum (Equations 17 and 18). The confidence interval around $h$ is $\pm 21.14 \mathrm{~W} \mathrm{~m}^{-2} \mathrm{~K}^{-1}$ (around the $25 \%$ ) and for $S_{o, s u r f}, \pm 0.0117$ (around the $9 \%$ ). The weighted least squares contours in the vicinity of the optimal solution (Figure 5 reveal that the parameters are highly correlated. This may be explained taking into account the low sensitivity of the states to modifications in the parameter values for the given experimental conditions. Figure 6 presents more detail about the evolution of the acrylamide, moisture and oil content together with the temperature for 10 different combinations of the parameter values within 
the confidence region, showing how some of the curves are not distinguishable. To improve sensitivity and thus confidence intervals further, optimally designed (Balsa-Canto et al., 2007), experiments are required.

\subsection{Process optimization}

\subsubsection{Constant processing temperature}

The typical industrial process at constant oil temperature was first considered. The degrees of freedom are the processing temperature and the process duration. Figure 7 presents the optimal oil temperature obtained for each process duration and the predicted acrylamide content for each value of the decision variable. As expected, the lower the oil temperature the lower the acrylamide content and the longer the process.

Results reveal that a reduction in the oil temperature from $180^{\circ} \mathrm{C}$ to $150^{\circ} \mathrm{C}$ translates into a reduction of around the $70 \%$ in acrylamide content and an increase of the $25 \%$ in the process duration. Since the process duration is critical for the production rate, and no recommendations or constraints are yet available on the maximum admissible acrylamide content, a good compromise would be to use intermediate temperature values $\left(165-170^{\circ} \mathrm{C}\right)$ during 80-85 $s$.

\subsubsection{Variable processing temperature}

Results from the previous section raise the question, is it possible to further reduce acrylamide content and process duration by manipulating operating conditions? The recent work by Bassama et al. (2012) shows, via simulation, that the application of a two-step temperature profile, with a 
higher temperature at the beginning of the process may help to control acrylamide formation in plantain.

The general dynamic optimization problem was solved for different maximum process durations (80, 85, 90 and 95 seconds) and different numbers of maximum heating zones. First, the simplest case with two heating zones is considered assuming a fixed duration $\left(t_{1}\right)$ for the first heating zone. Results (Table 1 and Figure 8 ) reveal that reductions of up to $16.5 \%$ can be achieved by using two different heating zones. For all cases, the optimum corresponds to using a larger temperature at the beginning of the process and a lower temperature at the end of the process. As expected, for the shortest processes, higher temperatures have to be used in order to assess the final moisture content constraint. Using higher temperatures and shorter process durations induces a significant increase on the acrylamide content. For instance, comparing results for processes lasting $80 \mathrm{~s}$ and $85 \mathrm{~s}$, an increase of the $6 \%$ in process duration translates into an increase of around the $30 \%$ in final acrylamide content. Regarding the duration of the first heating zone, it seems reasonable to use $30-40 \mathrm{~s}$, since the process is flexible enough to comply with the constraints and minimize acrylamide content while reducing energy consumption as compared to the case with $t_{1}=20 \mathrm{~s}$.

Further improvements may be achieved if more flexibility is allowed (see Tables 2 and Figures 9 and 10). In this regard, the optimal profiles confirm that using a larger number of heating zones may improve results for shorter processes. In principle, five different heating zones offer the best compromise process duration and acrylamide reduction. Optimal profiles result in the use of a high temperature at the beginning of the process during a short 
period of time and a gradual decrease of the temperature until the end of the process. For the longest process, the use of two heating zones is again the optimum, but note that, using shorter heating times calls for the use of higher temperatures.

\section{Conclusions}

This work presented the formulation of a general dynamic optimization problem devoted to compute the oil temperature profile that guaranties the desired moisture content while minimizing final acrylamide content subject to operation constraints and the process dynamics which is described by means of a rigorous porous media based model taken from the literature.

In a first step, the unknown model parameters were identified by means of experimental data fitting. The problem was formulated as a general optimization problem to compute the value of the heat transfer coefficient and the oil saturation constant that minimize the distance between the experimental data and model predictions as measured by the weighted least squares function. The quality of the parameter estimates was assessed with confidence intervals obtained using the Hessian of the weighted least squares function at the optimum. The fitted model presents satisfactory predictive capabilities therefore being suitable for process optimization purposes.

A dynamic optimization problem was then defined to compute optimal process operation conditions. Several scenarios were tested to decide on the number of maximum heating zones and process duration. Results revealed that the simplest case, using two optimally designed heating zones, already reduces the final acrylamide content up to $16.5 \%$ when comparing with the 
333 traditional operation conditions. Further improvements may be achieved if 334 the number of heating zones is increased to 5 .

335 As a general conclusion the use of a short high temperature zone at the 336 beginning with a progressive decrease in zone temperatures was found to 337 be the optimal design showing significant advantages over nominal constant 338 temperature processes; thus opening new avenues for the design of industrial 339 frying processes. 


\section{Acknowledgements}

The authors acknowledge financial support from EU [CAFE FP7-KBBE2007-1(212754)], Spanish Ministry of Science and Innovation [SMART-QC AGL2008-05267-C03-01], Xunta de Galicia [IDECOP 08DPI007402PR] and CSIC [PIE201270E075]. A. Arias-Méndez acknowledges financial support from the JAE-CSIC program.

\section{References}

\section{References}

Alvarez, M. D., Morillo, M. J., Canet, W. (2000). Characterization of the frying process of fresh and blanched potato strips using response surface methodology. Eur Food Res Technol 211(5), 320-335.

Ateba, P., Mittal, G. S. (1994). Modelling the deep-fat frying of beef meatballs. Int. J. Food Sci. Technol. 29, 429.

Balsa-Canto, E., Banga, J. R. (2011). AMIGO, a toolbox for advanced model identification in systems biology using global optimization. Bioinformatics 27(16), 2311-2313.

Balsa-Canto, E., Rodriguez-Fernandez, M., Banga, J. R. (2007). Optimal design of dynamic experiments for improved estimation of kinetic parameters of thermal degradation. J. Food Eng. 82, 178-188.

Banga, J. R., Balsa-Canto, E., Alonso, A. A. (2008). Quality and safety models and optimization as part of computer-integrated manufacturing. Compr. Rev. Food Sci. F 7 (1), 168-174. 
Banga, J. R., Balsa-Canto, E., Moles, C. G., Alonso, A. A. (2003). Improving food processing using modern optimization methods. Trends Food Sci. \& Technol. 14(4), 131-144.

Bassama, J., Brat, P., Boulanger, R., Gnata, Z., Bohuon, P. (2012). Modeling deep-fat frying for control of acrylamide reaction in plantain. J. Food. Eng. $113(1), 156-166$.

Brennan, J. G., 2006. Food processing handbook. Wiley-VCH, Technology and Engineering.

Brigatto-Fontes, L. C., Oliveira, F. G., Collares-Queiroz, F. P. (2011). Optimization of the deep-fat frying process of sweet potato chips in palm olein or stearin. American Journal of Food Technology 45, 348-361.

Choi, Y., Okos, M. R. (1986). Thermal properties of liquid foods - review. Physical and Chemical Properties of Food, (American Society of Agricultural Engineers, St. Joseph, MI, USA).

Egea, J. A., Balsa-Canto, E., Garcia, M. G., Banga, J. R. (2009). Dynamic optimization of nonlinear processes with an enhanced scatter search method. Ind. \& Eng. Chem. Res. 48 (9), 4388-4401.

Egea, J. A., Rodriguez-Fernandez, M., Banga, J. R., Marti, R. (2007). Scatter search for chemical and bio-process optimization. J. Global Optim. 37 (3), 481-503.

Farkas, B. E., Singh, R. P., Rumsey, T. R., 1996. Modeling heat and mass transfer in immersion frying. i, model development. Journal of Food Engineering 29 (2), 211-226. 
Garayo, J., Moreira, R. (2002). Vacuum frying of potato chips. J. Food Eng. 55 (2), 181 - 191.

Granda, C. (2005). Kinetics of acrylamide formation in potato chips. Ph.D. thesis, Texas A\&M University, USA.

Halder, A., Dhall, A., Datta, A. K. (2007). An improved, easily implementable, porous media based model for deep-fat frying - part I: Model development and input parameters. Food Bioprod. Process. 85(C3), 209219.

Medeiros-Vinci, R., Mestdagh, F., Meulenaer, B. D. (2011). Acrylamide formation in fried potato products. present and future, a critical review on mitigation strategies. Food Chem. DOI:10.1016/j.foodchem.2011.08.001.

Mestdagh, F., Wilde, T. D., Fraselle, S., Goaert, Y., Ooghe, W., Degrooodt, J. M., Verhe, R., Peteghem, C. V., Meulenaer, B. D. (2008). Optimization of the blanching process to reduce acrylamide in fried potatoes. LWT-Food SCI \& Technol 41(9), 1648-1654.

Moreira, R. G., Palau, J. E., Sun, X. (1995). Deep-fat frying of tortilla chips: an engineering approach. Food Technology 49 (4), 146-150.

Ni, H., Datta, A. K. (1999). Heat and moisture transfer in baking of potato slabs. Drying Technology 17(10), 2069-2092.

Pedreschi, F., Leon, J., Mery, D., Moyano, P. (2006). Development of a computer vision system to measure the color of potato chips. Food Res. Int. 39 (10), 1092-1098. 
Pedreschi, F., Moyano, P., Kaack, K., Granby, K. (2005). Color changes and acrylamide formation in fried potato slices. Food Res. Int. 38 (1), 1-9.

Saguy, I. S., Dana, D. (2003). Integrated approach to deep fat frying: engineering, nutrition, health and consumer aspects. J. Food Eng. 56(2-3), $143-152$.

Tareke, E., Rydberg, P., Karlsson, P., Eriksson, S., Tornqvist, M. (2002). Analysis of acrylamide, a carcinogen formed in heated foodstuffs. J. Agricult. Food Chem. 50 (17), 4998-5006.

Thussu, S., Datta, A. K. (2012). Texture prediction during deep frying: A mechanistic approach. J. Food Eng. 108 (1), 111-121.

Tseng, Y. C., Moreira, R., Sun, X. (1996). Total frying-use time effects on soybean-oil deterioration and on tortilla chip quality. Int. J. Food Sci. Technol. 31, 287-294.

Walter, E., Pronzato, L. (1997). Identification of Parametric Models from Experimental Data. Springer, Masson.

Warning, A., Dhall, A., Mitrea, D., Datta, A. (2012). Porous Media Based Model for Deep-Fat Vacuum Frying Potato Chips. J. Food Eng. 110 (3), 428-440.

Zhang, Y., Zhang, G., Zhang, Y. (2005). Occurrence and analytical methods of acrylamide in heat-treated foods: Review and recent developments. J. Chromatography A 1075, $1-21$. 


\section{Appendix A. Mathematical model of the frying process}

A multiphase porous media model describing heat, mass, and momentum transfer within a potato chip during atmospheric frying, based on the formulation by Warning et al. (2012), was used in this work. Mass and energy conservation equations include diffusive, capillary, and convective transport. Momentum conservation was introduced by means of Darcy's equation. A non-equilibrium water evaporation rate and a kinetic model for acrylamide formation based on chip temperature are also considered. Here a brief overview of the most important model assumptions and equations is presented. Warning et al. (2012) provides an indepth description of the model equations.

\section{Mass conservation}

The following three equations solve for the liquid water, oil, and gas saturation in the pores.

$$
\begin{aligned}
& \frac{\partial}{\partial t}\left(\varphi \rho_{w} S_{w}\right)+\nabla\left(u_{w} \rho_{w}\right)=\nabla\left(D_{w, c a p} \nabla\left(\varphi \rho_{w} S_{w}\right)\right)-I \\
& \frac{\partial}{\partial t}\left(\varphi \rho_{o} S_{o}\right)+\nabla\left(u_{o} \rho_{o}\right)=\nabla\left(D_{o, c a p} \nabla\left(\varphi \rho_{w} S_{o}\right)\right) \\
& S_{g}=1-S_{w}-S_{o}
\end{aligned}
$$

To solve for the mass water vapor fraction of air and water vapor, binary diffusion equation is used.

$$
\begin{aligned}
& \frac{\partial}{\partial t}\left(\varphi \rho_{g} S_{g} \omega_{v}\right)+\nabla\left(u_{g} \rho_{g} \omega_{v}\right)=\nabla\left(\varphi S_{g} \frac{C_{g}^{2}}{\rho_{g}} M_{a} M_{v} D_{e f f, g} \nabla x_{v}\right)+I(\mathrm{~A} .4) \\
& \omega_{a}=1-\omega_{v}
\end{aligned}
$$


444

Momentum conservation

The pressure and fluid velocities are calculated using Darcy's equation where pressure increases and decreases with the evaporation of liquid water.

$$
\begin{aligned}
& \frac{\partial}{\partial t}\left(\varphi \rho_{g} S_{g}\right)+\nabla\left(-\rho_{g} \frac{k_{i n, g}^{p} k_{r, g}^{p}}{\mu_{g}} \nabla P\right)=I \\
& u_{i}=-\frac{k_{i n, i}^{p} k_{r, i}^{p}}{\mu_{i}} \nabla P
\end{aligned}
$$

\section{Energy conservation}

The temperature is calculated using effective properties as shown by Warning et al. (2012) and where evaporation of water uses a non-equilibrium formulation.

$$
\begin{aligned}
& \frac{\partial}{\partial t}\left(\rho_{e f f} c_{p, e f f} T\right)+\nabla\left(\left(\rho c_{p} u\right)_{f l u i d} T\right)=\nabla\left(k_{e f f} \nabla T\right)-\lambda I \\
& I=K\left(\rho_{v, e q}-\rho_{v}\right) S_{g} \varphi
\end{aligned}
$$

Acrylamide formation and degradation

The transport of acrylimide is assumed only in the liquid water and solid component while the rate of formation is given by Granda (2005) in A.11.

$$
\begin{aligned}
& \left.\frac{\partial}{\partial t} c_{A A}+\nabla\left(u_{w} S_{w} \varphi c_{A A}\right)=\nabla\left(D_{A A} \nabla\left(\left\{S_{w} \varphi+(1-\varphi)\right\} c_{A A}\right)\right)+r_{A A} .10\right) \\
& \frac{d\left(c_{A A}(t)\right)}{d t}=r_{A A}=\frac{14.9 A \exp \left(\frac{-2625.8}{T}\right) \exp \left\{-14.9 \exp \left(\frac{2625.8}{T}\right)\left(t-t_{\rho}\right)\right\}_{11}}{\left(1+\exp \left\{-14.9 \exp \left(\frac{-2625.8}{T}\right)\left(t-t_{o}\right)\right\}\right)^{2}}
\end{aligned}
$$


Boundary and initial conditions

The top and left of the potato chip is heated as shown in Figure 1. The other boundaries of the chip are insulated and impermeable. The boundary conditions (B.C.) are then given as:

B.C. for eq. A.2: $n_{w, \text { surf }}=u_{w} \rho_{w}+h_{m} \varphi S_{w}\left(\rho_{g, \text { surf }} \omega_{v, \text { surf }}-\rho_{v, \text { fryer }}\right)$

B.C. for eq. A.3: $S_{o, s u r f}=0.145$

B.C. for eq. A.5: $n_{v, \text { surf }}=u_{g} \rho_{g} \omega_{v}+h_{m} \varphi S_{g}\left(\rho_{g, \text { surf }} \omega_{v, \text { surf }}-\rho_{v, \text { fryer }}\right)$

B.C. for eq. A.7: $P_{\text {surf }}=P_{\text {fryer }}$

B.C. for Equation A.9: $q_{\text {surf }}=h\left(T_{o i l}-T\right)-\left(\lambda+c_{p, w} T\right) n_{w, s u r f}-c_{p, v} T n_{v, \text { surf }}-$ $c_{p, o} T_{o i l} n_{o, \text { surf }}$

B.C. for Equation A.11: $n_{A A, s u r f}=0$

$S_{o, \text { surf }}$ is estimated in this work by means of multi-experiment parametric identification.

The initial conditions at $t=0$ are zero for oil saturation, zero for acrylamide concentration, and $298 \mathrm{~K}$ for temperature. The initial water saturation is assumed to be 0.8 and the water vapor fraction is calculated as shown in Warning et al. (2012).

\section{Appendix A.0.3. Model parameters}

Input parameters are shown in Table A.3. Physical and thermal properties are for a raw potato. For the this model, $h$ and $S_{o, \text { surf }}$ were estimated by a constant value that gave reasonable fit to the experimental moisture and oil content data respectively. 


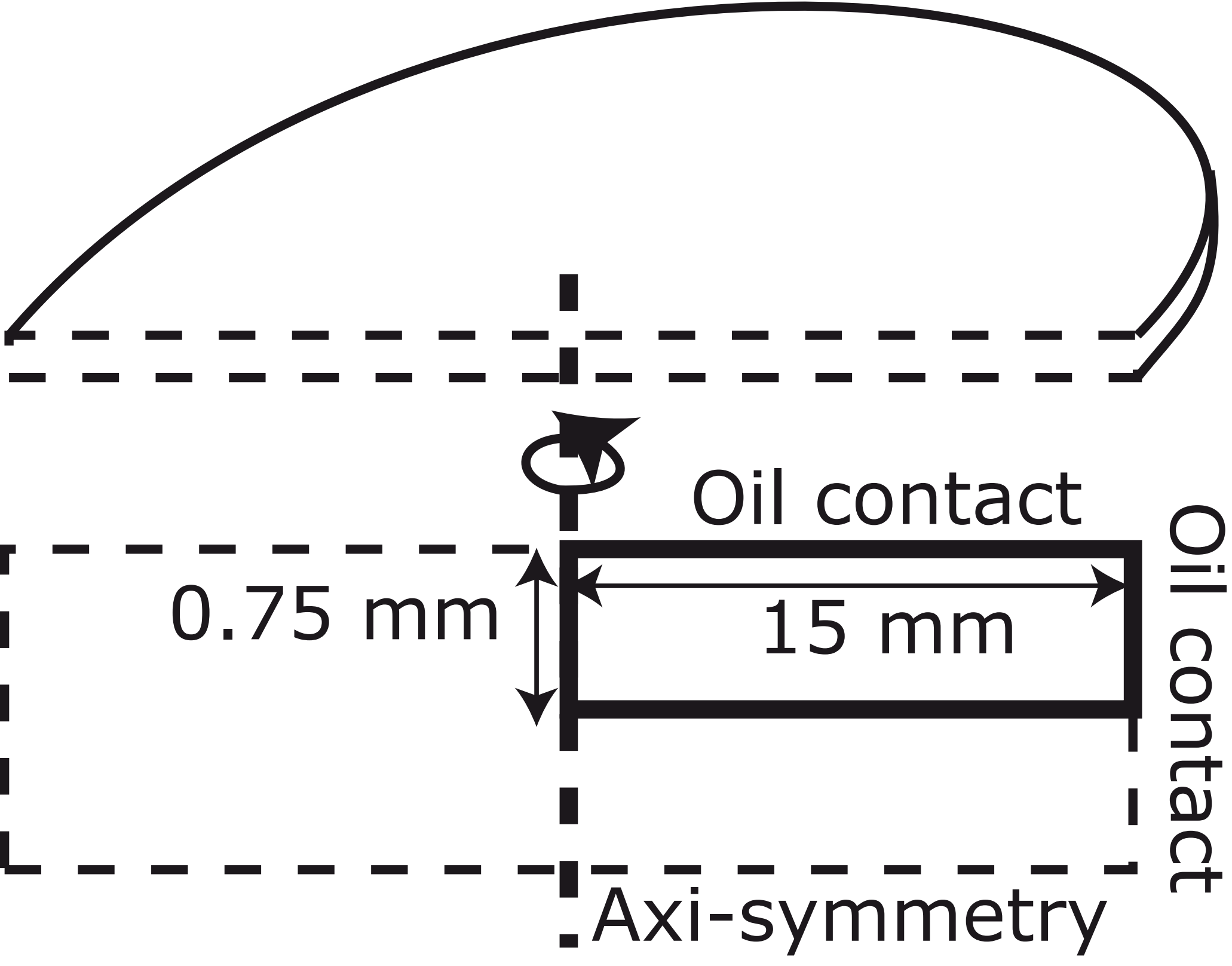




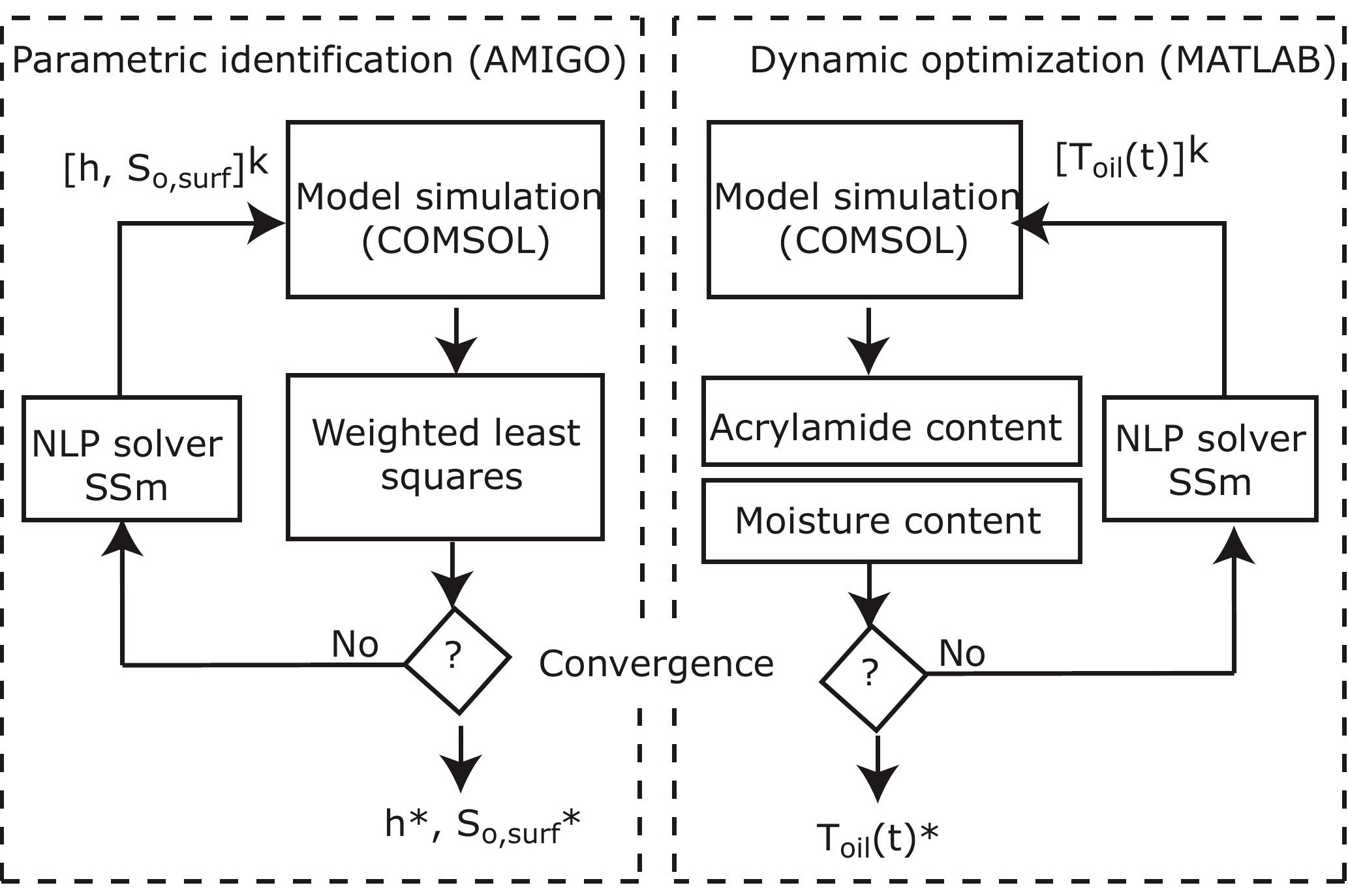



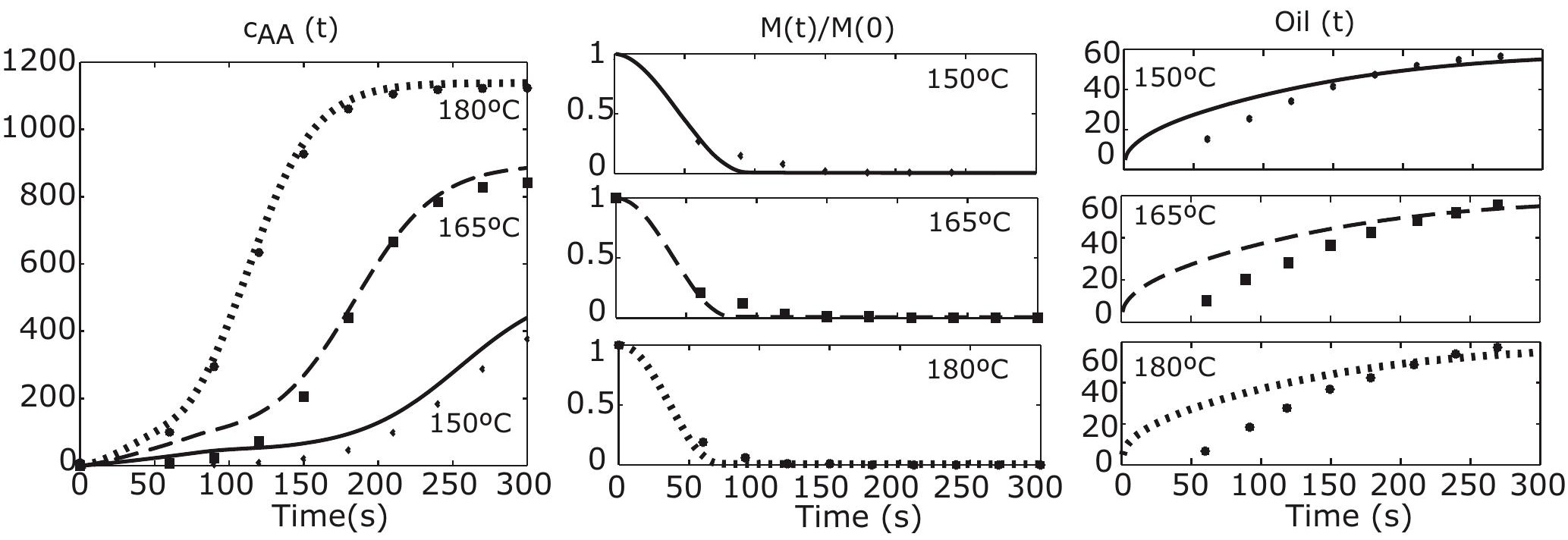
a)

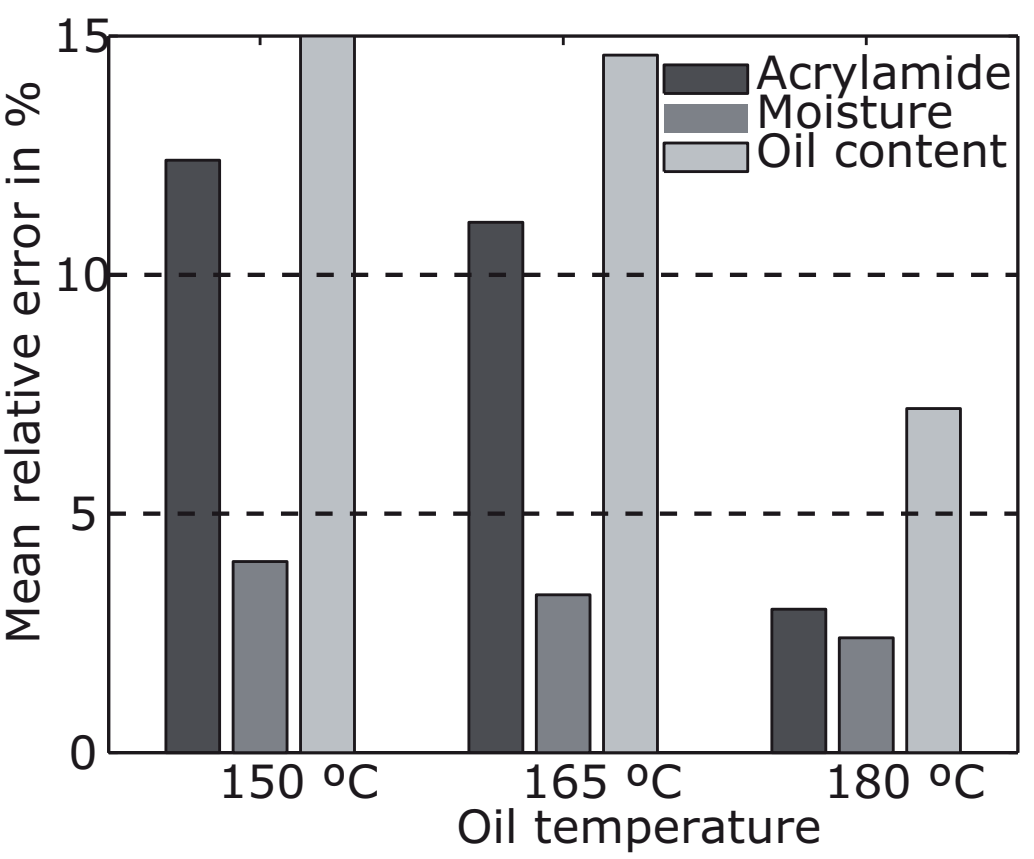

b)

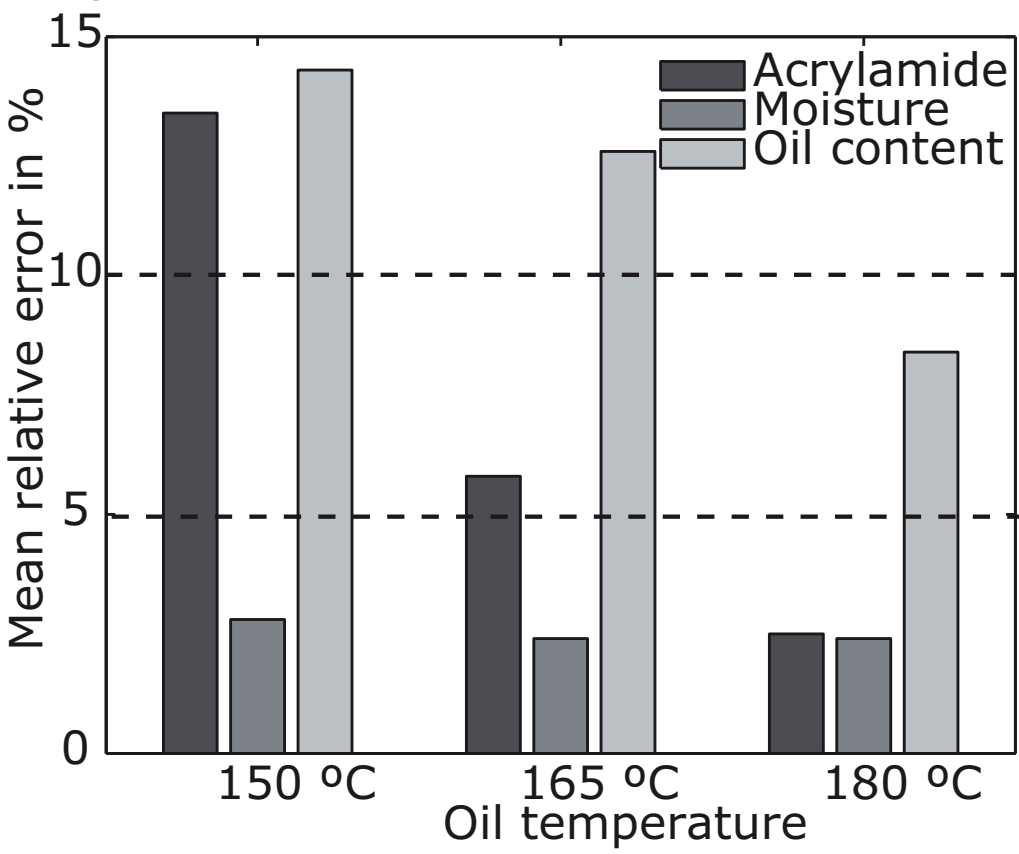




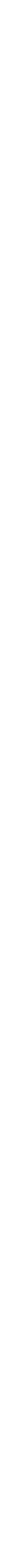


a)
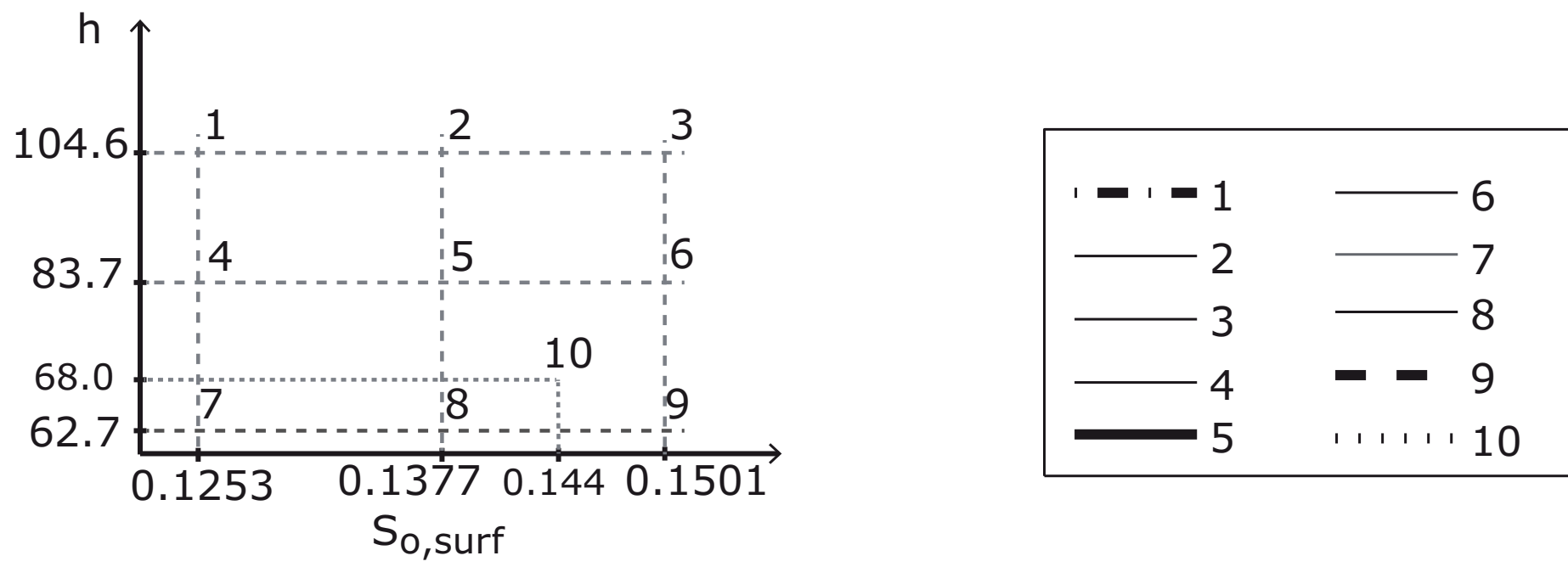

b)
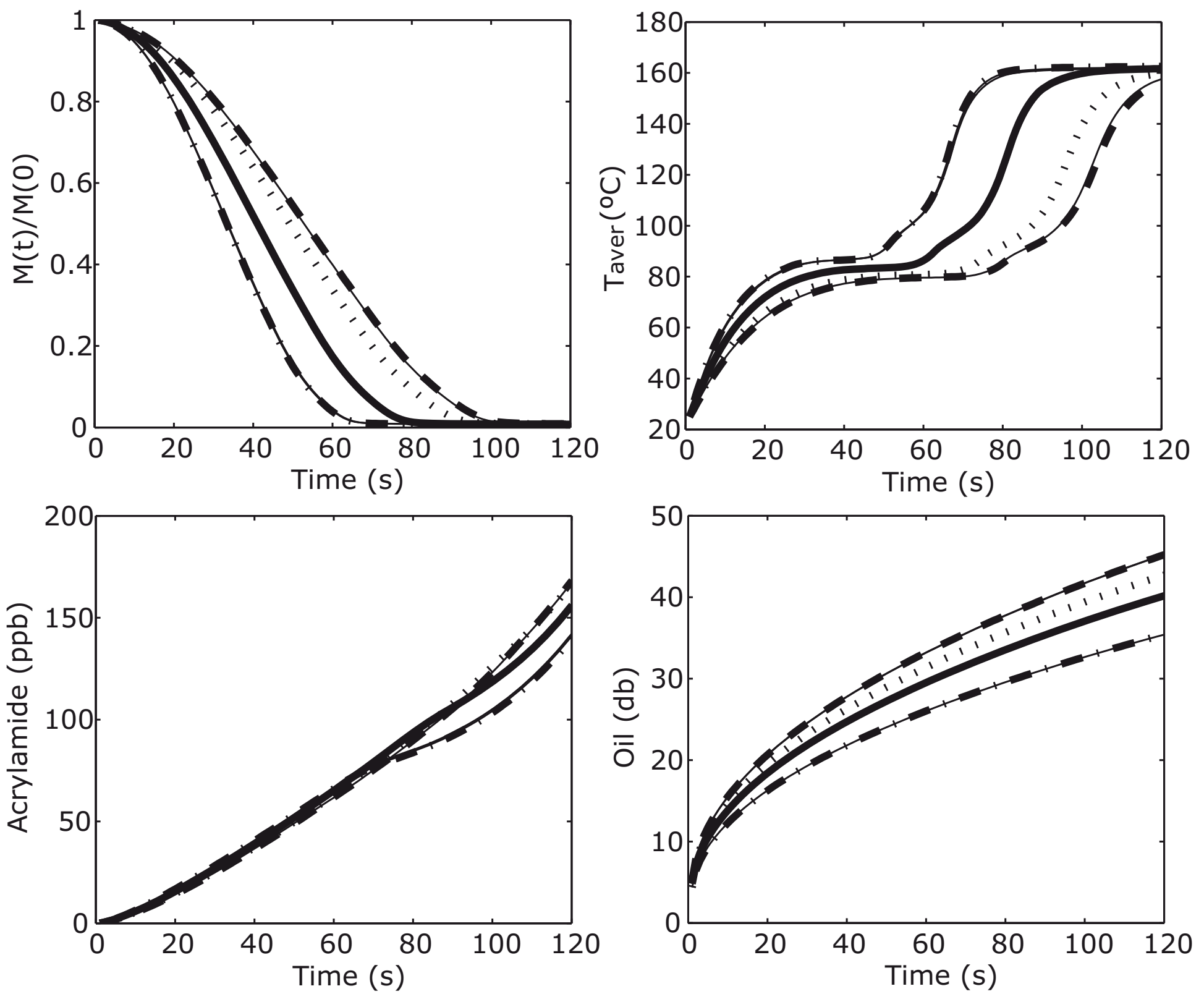


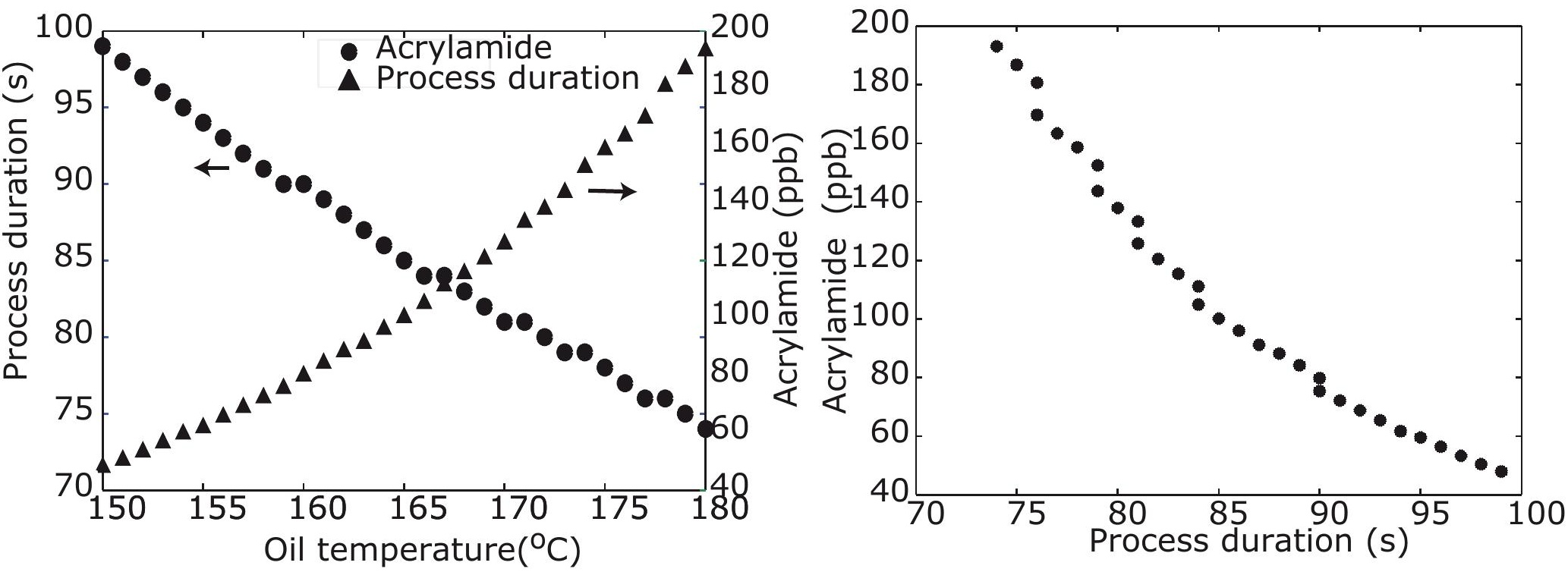



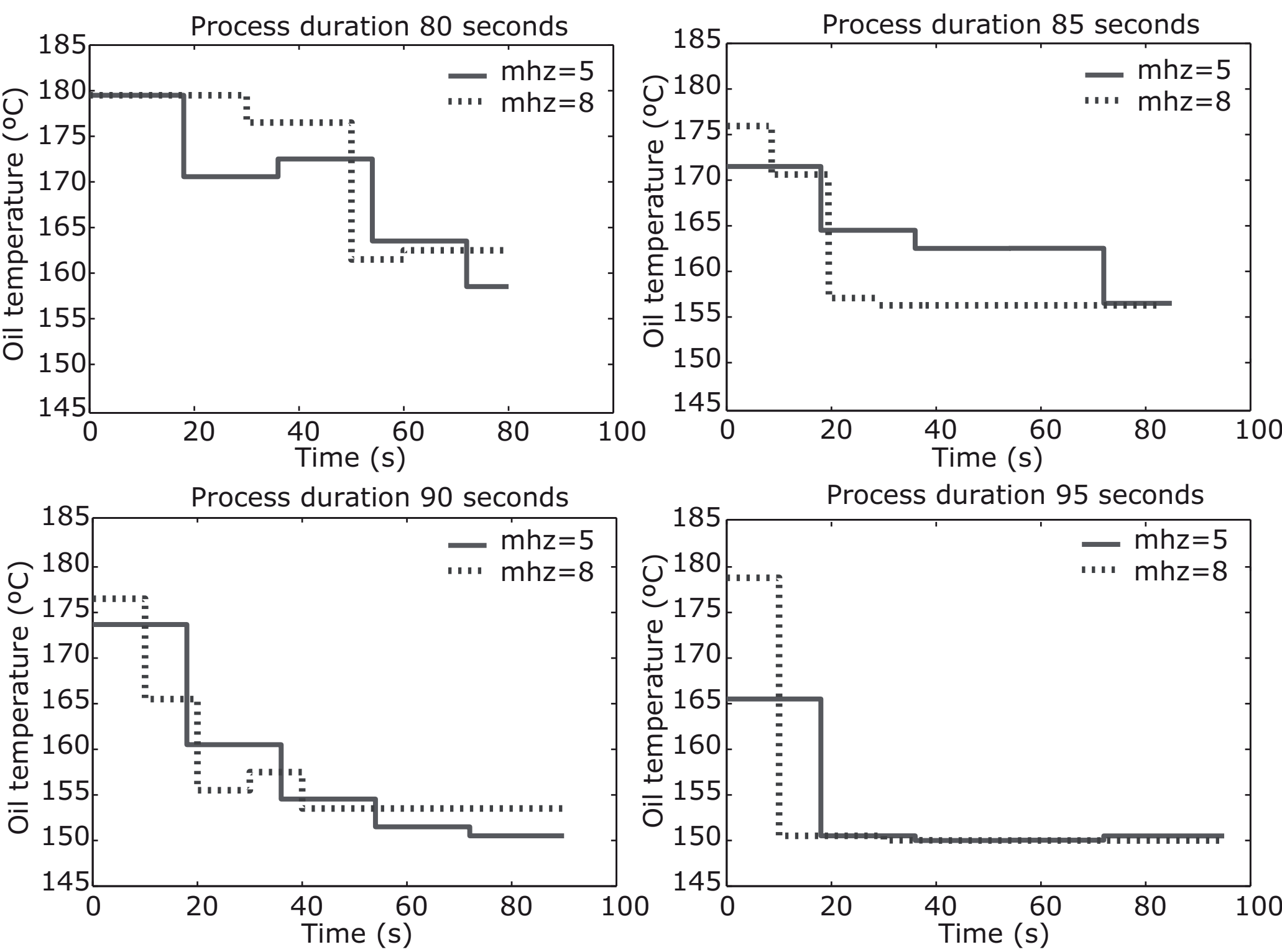


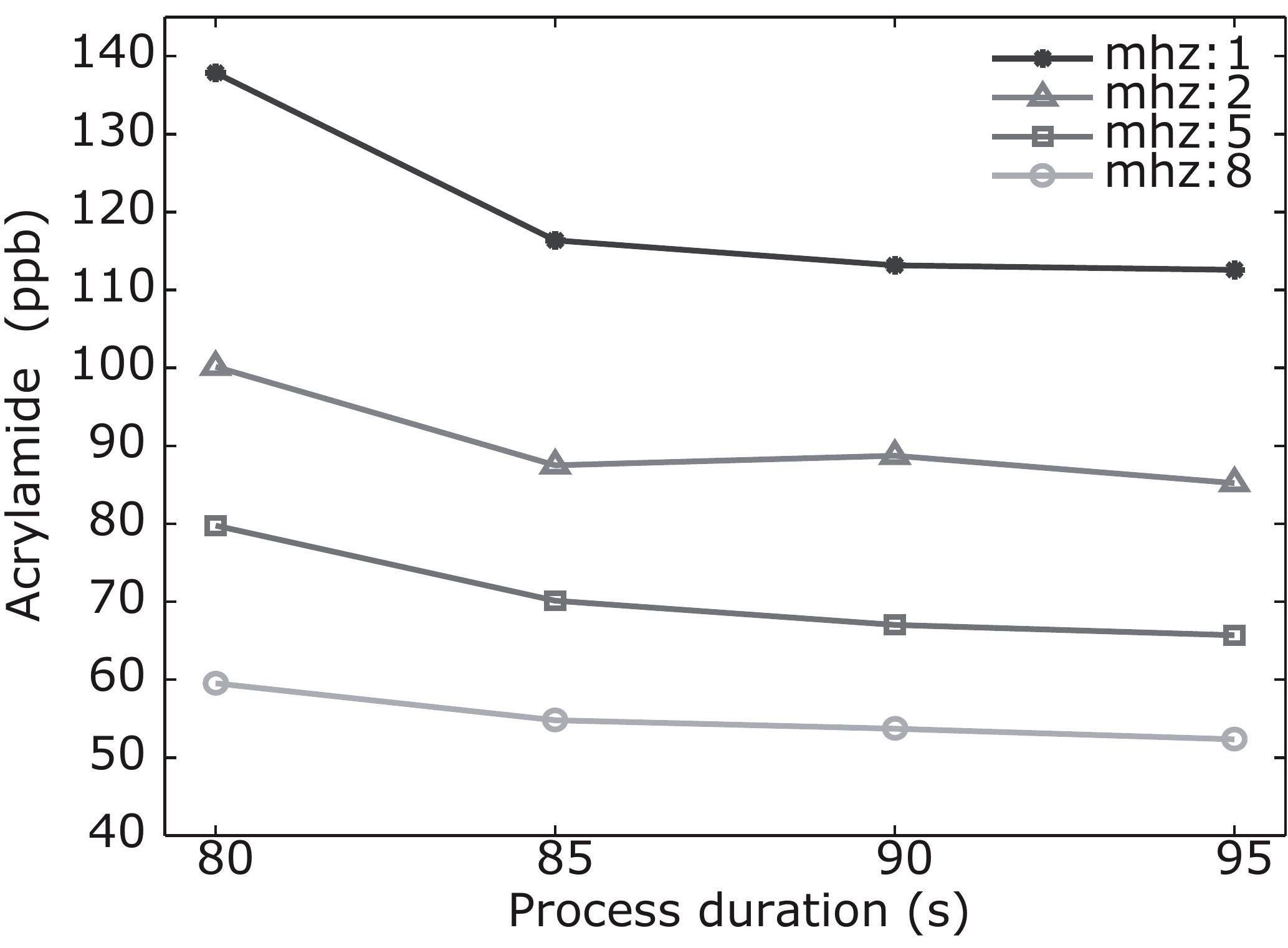




\section{Figure captions}

Figure 1. 2-Dimensional computational domain and geometry of the potato chip.

Figure 2. Optimization procedures: a) Parametric identification and b) Dynamic optimization.

Figure 3. Best fit: experimental data (dots) and model data (lines) of acrylamide, oil and moisture content at different process temperatures.

Figure 4. Mean relative prediction errors: a) Model with the original set of parameters, b) Model with the optimal value of the parameters.

Figure 5. Contour plot of the $J_{w l s q}$ in the vicinity of the optimal solution.

Figure 6. Evolution of the states for different combinations of parameter values within the confidence region.

Figure 7. Results of the process optimization problem under constant oil temperature: a) Process duration and final acrylamide content for different oil temperatures b) Pareto front.

Figure 8. Optimal oil temperature profiles for a maximum of two heating zones and different process durations.

Figure 9. Optimal operation conditions (oil temperatures) for the process using different numbers of heating zones and different maximum process durations.

Figure 10. Final acrylamide content at the optimal solutions for different numbers of maximum heating zones and process durations. 


\section{Highligths}

- We approach the dynamic optimization of the deep-fat frying of potato chips.

- The unknown parameters of a porous media based model are identified from data.

- The model presents good predictive capabilities and is thus used for optimization.

- We compare constant (traditional) with variable processing temperatures.

- Variable profiles maximize quality and safety while minimizing process duration. 
Table 1: Final Acrylamide content at the optimal solutions (2steps).

\begin{tabular}{ccccc}
\cline { 2 - 5 } & $\mathrm{t}_{f, \max }=80 \mathrm{~s}$ & $\mathrm{t}_{f, \max }=85 \mathrm{~s}$ & $\mathrm{t}_{f, \max }=90 \mathrm{~s}$ & $\mathrm{t}_{f, \max }=95 \mathrm{~s}$ \\
\hline$t_{1}=20 \mathrm{~s}$ & 119.7 & 87.7 & 68.2 & 53.2 \\
$t_{1}=30 \mathrm{~s}$ & 116.38 & 87.50 & 70.14 & 54.80 \\
$t_{1}=40 \mathrm{~s}$ & 115.085 & 90.14 & 70.00 & 55.23 \\
$t_{1}=70 \mathrm{~s}$ & 122.31 & 93.43 & 71.47 & 55.24 \\
\hline
\end{tabular}

Table 2: Final Acrylamide content at the optimal solutions.

\begin{tabular}{lcccc}
\cline { 2 - 5 } & $\mathrm{t}_{f}=80 \mathrm{~s}$ & $\mathrm{t}_{f} 85 \mathrm{~s}$ & $\mathrm{t}_{f}=90 \mathrm{~s}$ & $\mathrm{t}_{f}=95 \mathrm{~s}$ \\
\hline $\mathrm{mhz}=1$ & 137.87 & 100.16 & 77.06 & 59.55 \\
$\mathrm{mhz}=2$ & 116.38 & 87.50 & 70.14 & 54.80 \\
$\mathrm{mhz}=5$ & 113.16 & 87.43 & 67.03 & 53.72 \\
$\mathrm{mhz}=8$ & 112.60 & 85.24 & 65.72 & 52.35 \\
\hline
\end{tabular}


Appendix A.

Table A.3: Input parameters used in simulations.

\begin{tabular}{|c|c|c|c|c|}
\hline Parameter & Symbol & Value & Units & Source \\
\hline Heat transfer coefficient & $\mathrm{h}$ & 65 & $\mathrm{Wm}^{-2} K^{-1}$ & Estimated \\
\hline Mass transfer coefficient & $h_{m}$ & Eq. 50 & $\mathrm{~m} \mathrm{~s}^{-1}$ & (Warning et al., 2012) \\
\hline Latent heat vaporisation & $\lambda$ & Eq. 49 & $\mathrm{~J} \mathrm{~kg}^{-1}$ & (Warning et al., 2012) \\
\hline Porosity & $\varphi$ & 0.880 & & (Ni and Datta, 1999) \\
\hline Vapour diffusivity in air & $D_{e f f, g}$ & Eq. 35 & $\mathrm{~m}^{2} s^{-1}$ & (Warning et al., 2012) \\
\hline Evaporation constant & $K$ & 100 & $\mathrm{~s}^{-1}$ & (Warning et al., 2012) \\
\hline Surface oil saturation & $S_{o, \text { surf }}$ & 0.145 & & Estimated \\
\hline \multicolumn{5}{|l|}{ Density } \\
\hline water & $\rho_{w}$ & Eq. 44 & $\mathrm{~kg} \mathrm{~m} \mathrm{~m}^{-3}$ & (Warning et al., 2012) \\
\hline vapor & $\rho_{v}$ & Ideal gas & $\mathrm{kg} \mathrm{m} \mathrm{m}^{-3}$ & \\
\hline air & $\rho_{a}$ & Ideal gas & $\mathrm{kg} \mathrm{m}^{-3}$ & \\
\hline oil & $\rho_{o}$ & 879 & $\operatorname{kg~m}{ }^{-3}$ & (Tseng et al., 1996) \\
\hline solid & $\rho_{s}$ & Eq. 45 & $\mathrm{~kg} \mathrm{~m}^{-3}$ & (Warning et al., 2012) \\
\hline \multicolumn{5}{|l|}{ Specific heat capacity } \\
\hline water & $c_{p, w}$ & Eq. 36 & $\mathrm{Jkg}^{-1} \mathrm{~K}^{-1}$ & (Warning et al., 2012) \\
\hline vapor & $c_{p, v}$ & Eq. 37 & $\mathrm{Jkg}^{-1} \mathrm{~K}^{-1}$ & (Warning et al., 2012) \\
\hline air & $c_{p, a}$ & Eq. 38 & $\mathrm{Jkg}^{-1} \mathrm{~K}^{-1}$ & (Warning et al., 2012) \\
\hline oil & $c_{p, o}$ & 2223 & $\mathrm{Jkg}^{-1} \mathrm{~K}^{-1}$ & (Choi and Okos, 1986) \\
\hline solid & $c_{p, s}$ & 1650 & $\mathrm{Jkg}^{-1} \mathrm{~K}^{-1}$ & (Choi and Okos, 1986) \\
\hline \multicolumn{5}{|l|}{ Thermal conductivity } \\
\hline water & $k_{w}$ & Eq. 39 & $\mathrm{Wm}^{-1} \mathrm{~K}^{-1}$ & (Warning et al., 2012) \\
\hline
\end{tabular}




\begin{tabular}{|c|c|c|c|c|}
\hline vapor & $k_{v}$ & 0.17 & $\mathrm{Wm}^{-1} \mathrm{~K}^{-1}$ & (Choi and Okos, 1986) \\
\hline air & $k_{a}$ & 0.026 & $\mathrm{Wm}^{-1} \mathrm{~K}^{-1}$ & (Choi and Okos, 1986) \\
\hline oil & $k_{o}$ & 0.026 & $\mathrm{Wm}^{-1} \mathrm{~K}^{-1}$ & (Choi and Okos, 1986) \\
\hline solid & $k_{s}$ & 0.21 & $\mathrm{Wm}^{-1} \mathrm{~K}^{-1}$ & (Choi and Okos, 1986) \\
\hline \multicolumn{5}{|c|}{ Intrinsic permeability } \\
\hline water & $k_{i n, w}^{p}$ & $1 * 10^{-15}$ & $\mathrm{~m}^{2}$ & (Ni and Datta, 1999) \\
\hline air and vapor & $k_{i n, g}^{p}$ & 0.17 & $\mathrm{~m}^{2}$ & (Warning et al., 2012) \\
\hline oil & $k_{i n, o}^{p}$ & $1 * 10^{-15}$ & $\mathrm{~m}^{2}$ & (Ni and Datta, 1999) \\
\hline \multicolumn{5}{|c|}{ Relative permeability } \\
\hline water & $k_{r, w}^{p}$ & Eq. 41 & & (Warning et al., 2012) \\
\hline air and vapor & $k_{r, g}^{p}$ & Eq. 40 & & (Warning et al., 2012) \\
\hline oil & $k_{r, o}^{p}$ & Eq. 42 & & (Warning et al., 2012) \\
\hline \multicolumn{5}{|c|}{ Capillary diffusivity } \\
\hline water & $D_{w, c a p}$ & Eq. 32 & $\mathrm{~m}^{2} \mathrm{~s}^{-1}$ & (Warning et al., 2012) \\
\hline oil & $D_{o, c a p}$ & Eq. 33 & $\mathrm{~m}^{2} \mathrm{~s}^{-1}$ & (Warning et al., 2012) \\
\hline \multicolumn{5}{|l|}{ Viscosity } \\
\hline water & $\mu_{w}$ & Eq. 46 & Pa s & (Warning et al., 2012) \\
\hline air and vapor & $\mu_{g}$ & Eq. 47 & $\mathrm{Pas}$ & (Warning et al., 2012) \\
\hline oil & $\mu_{o}$ & Eq. 48 & $\mathrm{Pas}$ & (Warning et al., 2012) \\
\hline
\end{tabular}




\section{References}

Choi, Y., Okos, M. R., 1986. Thermal properties of liquid foods - review. Physical and Chemical Properties of Food, (American Society of Agricultural Engineers, St. Joseph, MI, USA).

Ni, H., Datta, A. K., 1999. Heat and moisture transfer in baking of potato slabs. Drying Technology 17(10), 2069-2092.

Pedreschi, F., Moyano, P., Kaack, K., Granby, K., 2005. Color changes and acrylamide formation in fried potato slices. Food Res. Int. 38 (1), 1-9.

Tseng, Y. C., Moreira, R., Sun, X., 1996. Total frying-use time effects on soybean-oil deterioration and on tortilla chip quality. Int. J. Food Sci. Technol. 31, 287-294.

Warning, A., Dhall, A., Mitrea, D., Datta, A., 2012. Porous Media Based Model for Deep-Fat Vacuum Frying Potato Chips. J. Food Eng. 110 (3), 428-440. 